\title{
Status effects of the German Excellence Initiative
}

\author{
Kerstin Bruckmeier ${ }^{1}$, Georg-Benedikt Fischer ${ }^{1}$ \& Berthold U. Wigger ${ }^{1}$ \\ ${ }^{1}$ Chair of Public Finance and Public Management, Karlsruhe Institute of Technology, Karlsruhe, Germany \\ Correspondence: Berthold U. Wigger, Chair of Public Finance and Public Management, Karlsruhe Institute of \\ Technology, Kronenstraße 34, D-76133 Karlsruhe, Germany. Tel: 49-721-6084-3731. E-mail: wigger@ kit.edu
}

Received: January 5, 2017

Accepted: February 13, 2017

Online Published: February 20, 2017

doi:10.5539/ijef.v9n3p177

URL: https://doi.org/10.5539/ijef.v9n3p177

\begin{abstract}
Being granted a title enhances the status of the awardee while its loss has an opposite effect. The present article examines whether the latter effect dominates the former in the sense that elevation is less status-enhancing than relegation is status-damaging. Thereto, we use the three consecutive rounds of the German Excellence Initiative (a publicly funded program to promote outstanding research at German universities) as a natural experiment. We provide evidence that the loss of the title as a so-called "elite university" had a negative effect on the number of first year students. In contrast, we find no evidence for a positive effect on the number of first year students when a university is granted the title. Placebo tests suggest that this effect is in fact due to the loss of the elite status and does not result from a decline in university quality.
\end{abstract}

Keywords: reputation effect, excellence initiative, enrolment numbers

\section{Introduction}

That the loss of a title weighs more heavily than its granting has been well-established. More than one hundred years ago, the German legal scholar Paul Laband (1907) wrote: "In the general perception, the award of a title does not nearly elevate the awardee to the extent that the loss of the title debases him"(Note 1). Thus, being awarded a title carries a substantial downside risk. The present paper demonstrates that such an effect does not only hold for individuals but also for institutions (Note 2). Based on data derived from the recent, Excellence Initiative" in the German university system we provide evidence that the granting of a prestigious title is in fact less status-enhancing than the loss of such a title is status-damaging.

The Excellence Initiative was established by the German federal government and the German states in 2005 to foster cutting-edge research at German public universities. It attracted widespread international attention (Note 3). The initiative granted financial awards to select universities based on the outcome of a highly competitive process that included an international peer review of each candidate institution's graduate schools, excellence clusters and institutional strategies. The acquisition of funds was thus perceived as very prestigious. Universities that were successful in acquiring funds in all three lines of the Excellence Initiative gained substantial recognition both in academia and the general public. Officially, these universities have been designated as "Universities of Excellence"; colloquially, they are referred to as "elite universities".

The selection process of the Excellence Initiative consisted of three rounds. In the first round, only three universities became elite universities. In the second round, another six universities gained this status. In the third and (thus far) final round, another five universities joined the elite club. In contrast to the first two rounds, it was also possible to lose the elite status in the third round, with the result that three universities in fact lost their elite status. There are currently eleven universities that enjoy elite status.

In the present paper, we study the extent to which the Excellence Initiative led to a measurable status enhancing or status damaging effect for those universities that either gained or lost the elite status. For this purpose we compare the development of enrolment numbers of first year students at elite and non-elite universities. Common sense suggests and the results of, e.g., Bowman and Bastedo (2009) show that the prestige of a university positively affects the decision of high school graduates on where to study (Note 4). We provide evidence that being awarded with the elite status as such did not have an effect on enrolment numbers. The revocation of the elite status, in contrast, had a significantly negative effect on these figures. Employing placebo tests we also show that this effect can in fact be attributed to the withdrawal of the elite status rather than to a decline in a university's quality after the title was granted. Only after the loss of the elite status did enrolment 
numbers react.

Of the sixteen German states, the present paper focuses on an analysis of a single state, Baden-Wuerttemberg. Methodologically, this focus has at least three key advantages. First, public universities in Germany are under the jurisdiction of the state rather than the federal government. Consequently, there are substantial differences between university policies of the states, especially with respect to funding. Within a state, in contrast, public universities are all subject to the same policy and, thus, are homogeneous in this respect. Second, the case of Baden-Wuerttemberg provides substantial variety with respect to the outcomes of the Excellence Initiative. Baden-Wuerttemberg has nine public universities. Five of these universities got the elite status in one of the three rounds of the Excellence Initiative and two of these five lost the elite status in the third round. Third, students in Germany are rather immobile; they tend to enroll at a university in close proximity to the place where they graduated from high school (Note 5). In Baden-Wuerttemberg elite and non-elite universities are in close proximity to one another. Therefore, Baden-Wuerttemberg provides a promising case for an examination of the effects of the Excellence Initiative on enrolment behavior.

Whether or not a university became an elite university and whether or not an elite university lost the elite status was, from a high school student's perspective, an exogenous event. Thus, in studying enrolment behavior of high school graduates, the Excellence Initiative can be seen as a natural experiment, in which elite universities are the treatment group and non-elite universities are the control group. We exploit the natural experiment character of the Excellence Initiative in our research design.

The remainder of the paper is structured as follows. Section two provides further information on the institutional background of the Excellence Initiative as well as the university sector in Baden-Wuerttemberg. Section three describes the dataset and the estimation strategy. Section four presents the main results. Section five concludes.

\section{Method}

\section{Institutional Background}

The German government - at both the national and the state levels - established several programs to strengthen the international competitiveness of the German research sector. The Excellence Initiative is one of these programs and probably the most visible one. In total, it provides almost 5 billion Euro for three lines of research funding. First, graduate schools to promote young academics; second, clusters of excellence to boost high quality research; and third, institutional strategies to strengthen a university's overall research profile. Universities that were successful in acquiring funds in all three lines were awarded the status of universities of excellence or elite universities.

Universities were selected in three subsequent rounds. The successful candidates of the first round were announced in October 2006. In this round three universities became elite universities, namely the University of Karlsruhe (today named Karlsruhe Institute of Technology), the Munich University of Technology and the Ludwig Maximilian University of Munich. The successful candidates of the second round were announced in October 2007. In this round another six universities joined the elite club, that is, the Heidelberg University, the University of Freiburg, the University of Konstanz, the RWTH Aachen University, the University of Göttingen and the Free University Berlin. The results of the third round were announced in July 2012. This round differed from the previous rounds in that all previously successful universities had to reapply. In particular, it was possible to lose the elite status. In the third round another five universities became elite universities, namely the University of Cologne, the University of Bremen, the Humboldt University of Berlin and the University of Tübingen. Three former elite universities lost the elite status: the University of Göttingen, the University of Freiburg and the Karlsruhe Institute of Technology. In the media these universities were presented as the losers of the Excellence Initiative.

The empirical analysis focuses on the universities in the state Baden-Wuerttemberg. Detailed information on whether and when universities in Baden-Wuerttemberg became elite-universities is given in Table 1. 
Table 1. Performance of universities in Baden-Wuerttemberg in the course of the third line of funding (institutional strategies) of the excellence initiative

\begin{tabular}{lccc}
\hline & Round 1 & Round 2 & Round 3 \\
Announcement of winners (w) and losers (1) & Oct 2006 & Oct 2007 & Jun 2012 \\
\hline University of Freiburg & & $\mathrm{w}$ & 1 \\
Heidelberg University & & $\mathrm{w}$ & 1 \\
University of Hohenheim & & & $\mathrm{w}$ \\
Karlsruhe Institute of Technology (KIT) & & & $\mathrm{w}$ \\
University of Konstanz & & \\
University of Mannheim & & & \\
University of Stuttgart & & & \\
University of Tübingen & & & \\
University of Ulm & & & \\
\hline
\end{tabular}

Note. Source: German Research Foundation.

\subsection{Dataset and Empirical Strategy}

The empirical analysis is based on observations of the nine universities of the state Baden-Wuerttemberg between the years 2003 and 2012. In order to identify the effect of the elite status on enrolment we use the annual percentage change in the number of first year students in the winter term in each year of the observation period, i.e., winter term 2003/2004 to winter term 2012/2013, as our dependent variable. We focus on winter terms because most German first year students enrol in the winter term. For some fields of study it is even obligatory to begin in the winter term. As information on the number of first year students is available separately for males and females, we control for potential gender differences. The data is provided by the Federal Statistical Office of Germany (Note 6).

To measure the effect that conferment of elite status has on university enrolment, we use the information provided in Table 1 and define two dummy variables. The variable elite_g indicates whether the university was granted the elite status in the first, second or third round. It assumes the value one in the winter term subsequent to the conferment of elite status. For the Karlsruhe Institute of Technology, for instance, the variable assumes the value one only in the winter term $2007 / 2008$, i.e., the first winter term after the status was conferred. Since the dependent variable measures annual percentage changes in enrolment, we only consider a one-time effect on enrolment numbers. The variable elite $w$ assumes the value one for those universities that lost the elite status in the third round of the Excellence Initiative. It, thus, assumes the value one for the University of Freiburg and the Karlsruhe Institute of Technology in the last year of the observation period.

Since we use panel data, we employ a fixed effects panel estimation approach. Our base specification considers the dependent variable $Y_{i t}$, i.e., the relative change in the number of first year students at university $i$ in year $t$, as a function of the explanatory variables $e l i t g_{i t}$ and $e l i t e_{-} w_{i t}$. Furthermore, it includes university fixed effects, $\delta_{i}$, and dummy variables for every year of the observation period, $\theta_{t}$. Thus, our base specification reads

where $\varepsilon_{i t}$ is the error term.

$$
Y_{i t}=\beta_{0}+\beta_{1} \text { elite_g } g_{i t}+\beta_{2} \text { elite_ } w_{i t}+\delta_{i}+\theta_{t}+\varepsilon_{i t}
$$

In an extension of the base specification we add a vector of control variables $X_{i t}^{\prime}$,

$$
Y_{i t}=\beta_{0}+\beta_{1} \text { elite_g } g_{i t}+\beta_{2} \text { elite_ } w_{i t}+\gamma X^{\prime}{ }_{i t}+\delta_{i}+\theta_{t}+\varepsilon_{i t}
$$

The vector $X_{i t}^{\prime}$ consists of the variables graduates $_{i t}$ graduates $_{i t}{ }^{2}$ and unemployment_rate $i t$. The variable graduates measures the annual percentage change in the number of new high school graduates in the region in which university $i$ is located. We expect that the number of first year students is affected by the supply of potential students, since empirical evidence suggests that German students are rather immobile. We employ information on the number of high school graduates in the administrative district (Landkreis) in which the university is located and the bordering administrative districts. The data is provided by the Statistical Offices of the German states and is available separately for males and females. We expect that an increase in the number of high school graduates in the region of the university positively affects the number of first year students. Since an increase in the number of high school graduates does not necessarily lead to a linear increase in the number of individuals that are suited for higher education (Kane, 1994) and, furthermore, a larger number of high school graduates might lead to crowding effects at the universities, we also include the variable graduates $^{2}$ and expect a negative effect of the respective coefficient.

The variable unemployment_rate measures the unemployment rate in the administrative district of university $i$. 
This variable reflects regional labor market conditions. Generally, it may affect the decision to enroll in higher education positively or negatively. If regional unemployment is high, the opportunity costs of studying are low. Furthermore, high unemployment increases incentives to study, as university graduates are less affected by unemployment. Yet, higher unemployment may imply a higher risk of human capital investment as university graduates may also be unemployed. Thus, we are agnostic with respect to the effect of the unemployment rate on enrolment numbers. Data on regional unemployment rates is provided by the Federal Employment Agency.

Table 2. Descriptive statistics of all variables

\begin{tabular}{ccccc}
\hline Variable & Mean & SD & Min & Max \\
\hline y_total & .0345802 & .1034875 & -.209 & .24 \\
y_male & .0338272 & .1330042 & -.3 & .409 \\
y_female & .038642 & .0922459 & -.161 & .269 \\
elite_g & .0864198 & .2827336 & 0 & 1 \\
elite_w & .0246914 & .1561497 & 0 & 1 \\
graduates_total & .1006173 & .1851037 & -.12 & .73 \\
graduates_male & .1048148 & .2074193 & -.16 & .8 \\
graduates_female & .1 & .175919 & -.1 & .72 \\
unemployment_rate & 5.654031 & 1.433166 & 3.448129 & 9.888337 \\
\hline
\end{tabular}

\section{Results}

Regression results are shown in Table 3 for all students, and for male and female students separately. As can be seen, there is no significant effect of receiving the elite status on the relative change in enrolment numbers in all model specifications and for all subgroups of students. Hence, it seems that high school graduates did not react to the alleged gain in reputation associated with a university's elite status. In contrast, the withdrawal of the elite status has a significantly negative effect in all model specifications and for all subgroups except for female students in the extended model.

That the gain in reputation associated with the elite status has no measurable effect on enrolment numbers could be explained by the fact that the elite status accrues to the university as a whole, rather than to individual schools or faculties. Individual schools or faculties at non-elite universities may be well perceived as being excellent. Likewise, they may be perceived as non-excellent at elite universities (Turner, 2007). To the extent that high school graduates react more to the reputation of the schools or faculties of their field of study than to the reputation of the university as a whole, one would expect that the relationship between enrolment numbers and a university's elite status is weak as our results suggest. However, the same line of argument should also apply to the effect of a loss of the elite status on enrolment numbers. Our results show that this is not the case. They provide evidence that it is the loss of the elite status that counts, whereas the gain of the elite status does not. In order to explain this discrepancy, prospect theory or private information arguments as outlined in the introduction may be more promising.

Table 2. Results of the fixed effects estimation separately for all, male and female first year students

\begin{tabular}{|c|c|c|c|c|c|c|}
\hline \multirow[b]{2}{*}{ elite_g } & \multicolumn{2}{|c|}{ All } & \multicolumn{2}{|c|}{ Males } & \multicolumn{2}{|c|}{ Females } \\
\hline & 0.00333 & 0.0133 & 0.0155 & 0.00357 & -0.0174 & -0.0144 \\
\hline & $(0.0194)$ & $(0.0310)$ & $(0.0266)$ & $(0.0359)$ & $(0.0280)$ & $(0.0363)$ \\
\hline \multirow[t]{2}{*}{$e l i t e \_w$} & $-0.0747 * *$ & $-0.0726^{*}$ & $-0.0676^{* *}$ & $-0.106^{* *} *$ & $-0.0584 * *$ & -0.0520 \\
\hline & $(0.0226)$ & $(0.0320)$ & $(0.0276)$ & $(0.0366)$ & $(0.0240)$ & $(0.0365)$ \\
\hline \multirow[t]{2}{*}{ graduates } & & $0.771^{* * *}$ & & $0.509 * * *$ & & 0.106 \\
\hline & & $(0.210)$ & & $(0.128)$ & & $(0.144)$ \\
\hline \multirow[t]{2}{*}{ graduates $^{2}$} & & $-0.969 * * *$ & & $-0.727 * * *$ & & -0.105 \\
\hline & & $(0.245)$ & & $(0.182)$ & & $(0.162)$ \\
\hline \multirow[t]{2}{*}{ unemployment_rate } & & 0.0144 & & -0.0149 & & 0.0161 \\
\hline & & $(0.0323)$ & & $(0.0326)$ & & $(0.0275)$ \\
\hline \multirow[t]{2}{*}{ Constant } & 0.0291 & -0.170 & -0.0219 & -0.0286 & $0.0871 * * *$ & -0.157 \\
\hline & $(0.0173)$ & $(0.265)$ & $(0.0247)$ & $(0.155)$ & $(0.0212)$ & $(0.226)$ \\
\hline Observations & 81 & 81 & 81 & 81 & 81 & 81 \\
\hline R-squared & 0.462 & 0.537 & 0.572 & 0.642 & 0.286 & 0.293 \\
\hline
\end{tabular}

Clustered standard errors in parentheses

*** $\mathrm{p}<0.01, * * \mathrm{p}<0.05, * \mathrm{p}<0.1$ 
The coefficients of the control variables show the expected signs. Only the number of high school graduates and its square have a significant effect on enrolment numbers. The higher is the number of new high school graduates in a university's region, the higher are that university's enrolment numbers, though this effect becomes smaller when the number of high school graduates becomes larger. These results are consistent with previous observations that German high school graduates are rather immobile.

Our results show a significant negative relation between enrolment numbers and the revocation of the elite status. This, however, may be spurious correlation as those universities who lost the elite status may have fallen in quality so that both the loss of the elite status and the decrease in enrolment numbers are a result of the quality decrease (Note 7). In order to account for this contingency, we consider two placebo tests by assuming that the withdrawal of the elite status did not take place in 2012, but already in 2011 or, respectively, 2010. If the decrease in a university's enrolment numbers resulted from a decrease in that university's quality after the university gained the elite status, the placebo loss of the elite status should show a negative effect on that university's enrolment numbers.

Table 4 contains the results of the placebo tests. To enable a better overview, Table 4 does not distinguish between males and females, but confines attention to all first year students. The variables elite_ $w_{t-1}$ and elite_ $w_{t-2}$ denote the dummies for a placebo withdrawal of the elite status in 2011 and 2010, respectively. As can be seen from Table 4, the coefficients of these dummies are insignificant in all specifications of the model, they even differ in sign between the different specifications. The effects of all other covariates, in contrast, remain unchanged. We thus conclude that it was in fact the withdrawal of the elite status in 2012, which led to the decrease in enrolment numbers.

Table 4. Results of the fixed effects estimation: Placebo test, loss of the elite status in 2011(columns 2 and 3) and 2010 (columns 4 and 5)

\begin{tabular}{|c|c|c|c|c|}
\hline \multirow[b]{2}{*}{ elite_g } & \multicolumn{4}{|c|}{ All } \\
\hline & 0.0165 & 0.0255 & 0.0154 & 0.0237 \\
\hline & $(0.0176)$ & $(0.0266)$ & $(0.0188)$ & $(0.0282)$ \\
\hline \multirow[t]{2}{*}{ elite_w_t-1 } & 0.0562 & 0.0532 & & \\
\hline & $(0.0573)$ & $(0.0803)$ & & \\
\hline \multirow[t]{2}{*}{ elite_$w_{-} t-2$} & & & -0.0351 & -0.0546 \\
\hline & & & $(0.0518)$ & $(0.0365)$ \\
\hline \multirow[t]{2}{*}{ graduates } & & $0.772 * * *$ & & $0.796 * * *$ \\
\hline & & $(0.205)$ & & $(0.198)$ \\
\hline \multirow[t]{2}{*}{ graduates $^{2}$} & & $-0.960 * * *$ & & $-0.980 * * *$ \\
\hline & & $(0.267)$ & & $(0.252)$ \\
\hline \multirow[t]{2}{*}{ unemployment_rate } & & 0.0111 & & 0.0115 \\
\hline & & $(0.0332)$ & & $(0.0317)$ \\
\hline \multirow[t]{2}{*}{ Constant } & 0.00805 & -0.144 & 0.00841 & -0.149 \\
\hline & $(0.0160)$ & $(0.272)$ & $(0.0171)$ & $(0.260)$ \\
\hline Observations & 81 & 81 & 81 & 81 \\
\hline R-squared & 0.459 & 0.534 & 0.456 & 0.534 \\
\hline
\end{tabular}

Clustered standard errors in parentheses.

*** $\mathrm{p}<0.01, * * \mathrm{p}<0.05, * \mathrm{p}<0.1$.

\section{Conclusion}

The present article has used the three consecutive rounds of the German Excellence Initiative as a natural experiment to study whether the award of a title is less status-enhancing than the withdrawal of the same title is status-damaging. To this end we measure the effects of the gain and the loss of the elite university status of the Excellence Initiative on a university's enrolment numbers. We provide evidence that the loss of the status as an elite university had a negative effect on the number of first year students. In contrast, we find no evidence for a positive effect on the number of first year students when a university is granted the elite status.

Our results point to a substantial downside risk of status conferment. For some universities initial success in the Excellence Initiative eventually resulted in a measurable reputation damage. Presumably, this ramification of the Excellence Initiative was not fully taken into account when the process of selecting elite universities was designed. As such, it appears that the same criteria were applied in the conferment of the elite status as well as in 
its revocation. The aforementioned legal scholar Paul Laband (1907) postulated that, because of the downside risk of holding a title, the hurdles for losing a title should be distinctly higher than for gaining it. Our results suggest that this consideration should also be taken into account in the design of public programs such as the Excellence Initiative.

\section{Acknowledgements}

Financial support by the German Federal Ministry of Education and Research (BMBF) (Grant No. 01PW11015) is gratefully acknowledged. Any opinions expressed here are those of the authors.

\section{References}

Besley, T., \& Ghatak, M. (2008). Status Incentives. American Economic Review, 98, 206-11. http://dx.doi.org/10.1257/aer.98.2.206

Bowman, N. A., \& Bastedo, M. N. (2009). Getting on the front page: Organizational reputation, status signals, and the impact of US News and World Report on student decisions. Research in Higher Education, 50, 415-436. http://dx.doi.org/10.1007/s11162-009-9129-8

Bruckmeier, K., \& Wigger, B. U. (2014). The Effects of Tuition Fees on Transition from High School to University in Germany. Economics of Education Review, 41, 14-23. http://dx.doi.org/10.1016/j.econedurev.2014.03.009

Frey, B. S., \& Neckermann, S. (2010). Awards as signals. CESifo Working Paper No. 3229. http://dx.doi.org/10.2139/ssrn.1709308

Frey, B. S., \& Neckermann, S. (2014). Awards are a special kind of signal. CREMA Working Paper No. 2014-04.

Gibbons, R., \& Murphy, K. J. (1992). Optimal Incentive Contracts in the Presence of Career Concerns. Journal of Political Economy, 100, 468-505. http://dx.doi.org/10.3386/w3792

Holmström, B. (1999). Managerial incentive problems: A dynamic perspective. Review of Economic Studies, 66, 169-182. http://dx.doi.org/10.1111/1467-937X.00083

Kahneman, D., \& Tversky, A. (1979). Prospect Theory: An Analysis of Decision under Risk. Econometrica, 47, 263-291. http://dx.doi.org/10.2307/1914185

Kane, T. J. (1994). College Entry by Blacks since 1970: The Role of College Costs, Family Background and Returns to Education. Journal of Political Economy, 120, 878-911. http://dx.doi.org/10.1086/261958

Laband, P. (1907). Das Recht am Titel. Deutsche Juristen-Zeitung, 12, 201-207.

MacLeod, W. B., \& Urquiola, M. (2009). Anti-Lemons: School reputation and educational quality. NBER Working Paper. http://dx.doi.org/15112.10.3386/w15112

Spiess, C. K., \& Wrohlich, K. (2010). Does distance determine who attends a university in Germany? Economics of Education Review, 29, 470-479. http://dx.doi.org/10.1016/j.econedurev.2009.10.009

Turner, G. (2007). Exzellenzinitiative und Geisteswissenschaften. In J. Gauger, \& G. Rüther, (Eds.), Warum die Geisteswissenschaften Zukunft haben! (pp. 436-446). Ein Beitrag zum Wissenschaftsjahr 2007, Freiburg im Breisgau: Herder.

\section{Notes}

Note 1. Own translation. In the German original it reads: "Die Verleihung eines Titels hebt den dadurch Ausgezeichneten in der allgemeinen Achtung bei weitem nicht in dem Grade, wie ihn die Entziehung des Titels herabsetzt". See Laband (1907, p. 206).

Note 2. Prospect Theory of Kahneman and Tversky (1979) suggests that individuals regret the loss of a title stronger than they appreciate its gain. That the damage to an individual's or institution's reputation resulting from the loss of a title is greater than the reputational enhancement of title conferment can likely be attributed to the revelation of (unfavorable) private information. Namely, an individual or an institution that loses a title reveals that it does not meet the expectations associated with the title. In contrast, an individual or institution that has never been awarded may still bear the potential to meet these expectations. Frey and Neckermann (2010, 2014) have addressed the role of awards as a means to reveal private information of both givers and receivers of awards. Besley and Ghatak (2008) study the role of awards as an incentive device to exert effort and to reduce the optimal level of monetary incentives. To our best knowledge, the impact of withdrawing an award has neither been addressed theoretically nor empirically in the economics literature. 
Note 3. France, for instance, started a similar initiative in 2011.

Note 4. A theoretical argument, which relies on asymmetric information and which supports this view, is provided by MacLeod and Urquiola (2009, p. 3): "Schools with good reputation are attractive to students because admission to such a school signals high ability".

Note 5. See, e.g., Spiess and Wrohlich (2010). Bruckmeier and Wigger (2014) show that regional trends in the number of high school graduates are a key predictor for trends in university enrolment numbers of first year students.

Note 6. See Statistisches Bundesamt, Fachserie 11, Reihe 4.1, various issues.

Note 7. In fact, the literature on managerial incentives suggests that a better reputation may reduce performance incentives. See Gibbons and Murphy (1992) and Holmström (1999).

\section{Copyrights}

Copyright for this article is retained by the author(s), with first publication rights granted to the journal.

This is an open-access article distributed under the terms and conditions of the Creative Commons Attribution license (http://creativecommons.org/licenses/by/4.0/). 